Open Access

\title{
The distribution of Chinese minority populations and its change based on the study of the Hu Huanyong line
}

\author{
Xiangdong Gao ${ }^{1^{*}}$, Xinxian Wang ${ }^{2}$ and Beiqian Zhu ${ }^{3}$
}

\author{
* Correspondence: \\ xdgao@ecnu.edu.cn \\ ${ }^{1}$ School of Public Administration, \\ The Center for Modern Chinese City \\ Studies, East China Normal \\ University, No. 3663, Zhongshan \\ North Road, Putuo District, \\ Shanghai, China \\ Full list of author information is \\ available at the end of the article
}

\begin{abstract}
The "Hu Line" and its demographic implications have attracted world-wide attention since the line was developed 80 years. Using GIS, this paper conducts a statistical analysis and systematic investigation on the stability and spatial of China's minority population growth on both sides of "Hu Line" by constructing the spatial database of China's census data from 1953 to 2010 and initiating a new method for identifying the spatial patterns of population growth. Major findings are as follows: (1) Spatial distribution of the minority population in China is not balanced, showing a significant spatial clustering; (2) The minority population is widely distributed across China, spreading to East China and all over the country; (3) The distribution pattern of China's minority population is characterized by extraordinary stability, with the ratio of south-east half to north-west half standing roughly at 75:25 from 1953 to 2010. We can thus say that the "Hu Line" is also a mutant line of China's minority population.
\end{abstract}

Keywords: Minority population, Hu line, Spatial pattern of population, Spatial analysis

\section{Background}

The "Distribution of China's Population," authored by well-known geographer $\mathrm{Hu}$ Huanyong and published in the "Journal of Geographical Sciences" in 1935, set the precedent for China's contemporary research on population geography. In the more than 80 years since the $\mathrm{Hu}$ Line was put forward, $\mathrm{Hu}$ and his followers have carried out extensive study focused on the Hu Line. The in-depth cause analysis found that food and employment are the important factors restricting the distribution of population in China (Ding and He 2015). Based on census and demographic data, the studies on population pattern and stability point out the subtle changes in the ratios of population to area on both sides of $\mathrm{Hu}$ Line and analyze the overall population pattern in China (Ge and Feng 2002; Liu et al. 2010). Validation has been made using new approaches and data. The simulation of China's population density (Lo 2001; Liu 2001; Liu et al. 2003; Tian et al. 2004; Zhuo et al. 2005; Zhuo et al. 2009), based on remote sensing data on land use and nighttime lamplight, came to the same conclusion as research relying on the $\mathrm{Hu}$ Line. There are also wide and extensive studies on the rationale of China's population distribution, China's population and environmental resilience (Yuan 1993; Wang 1998), are evident in the Hu Line (Wang 2014; Zhang et al. 2015), as is the close relationship of China's urban, transportation and economic patterns

(c) The Author(s). 2017 Open Access This article is distributed under the terms of the Creative Commons Attribution 4.0 International License (http://creativecommons.org/licenses/by/4.0/), which permits unrestricted use, distribution, and reproduction in any medium, provided you give appropriate credit to the original author(s) and the source, provide a link to the Creative Commons license, and indicate if changes were made. 
with Hu Line (Hu 1990; Wang 1997a, 1997b; Liu 2001; Dong et al. 2002; Li et al. 2009; Feng et al. 2007; Lv 2010), but few scholars examine the $\mathrm{Hu}$ Line from the perspective of ethnic populations.

With vast territory and many ethnic groups, China has gradually formed the traditional pattern of ethnic population distribution over thousands of years. For a long time, data collected about the most basic pattern of ethnic population distribution in China mainly followed the Han population in the central plains and the southeast coastal areas and noted the minority populations as mainly being in the border areas. However, with the rapid economic and social development and the continuous progress of urbanization, the distribution pattern of ethnic minority populations is undergoing changes due to the flow and migration of ethnic minorities on an increasing scale. The migration of minority populations, especially seen in changes in population distribution in traditionally ethnic minority areas are closely related to social and economic development, urbanization advancement, social harmony and stability and even border consolidation. Therefore, research on the distribution of minority populations and its changes is worth the attention of the government and academia.

In this regard, there has been significant progress in recent years. A variety of studies have been conducted, including macro-level research on spatial patterns and migration trends of minority population based on census data (Li 1995; Zhang and Zeng 2005; Luo 2008; Zheng 2013; Guo 2014; Jiao 2014), specific analysis of regional distribution characteristics and migration trends of minority populations on the provincial (or regional) scale (Zhao 1993; Ma 2000; Jin 2005; Liu et al. 2010; Lu 2009), and investigation into urban concentrations, living structure and structural characteristics of minority populations in cities (Ma and Jin 1997; Wang 1997a, 1997b; Shan 2006; Gao and Zhu 2014). However, these studies mainly focused on a few time points or a certain region, and failed to provide adequate information on the overall distribution and its continuous changes, undermining the explanation of causes. This paper systematically constructs a county-based spatial database covering six national population censuses from 1953 to 2010, and calculates and analyzes the distribution of minority populations in China through GIS spatial analysis. The research focus is on changes in the distribution of minority populations on both sides of $\mathrm{Hu}$ Line, and on spatial agglomeration characteristics and influencing factors, in order to provide support for guiding the orderly flow of minority population towards rational distribution and development of new-type urbanization.

\section{Data and methods}

\section{Data source and processing}

This paper uses data on resident populations in counties and cities identified in the six censuses conducted from 1953 to 2010, drawn from China's Population Census Data (1953-2010), and economic data including per capita gross domestic product (GDP) from China Statistical Yearbook for Regional Economy 2011. The minority population hereof refers to the population of all ethnic groups except the Han people (including unidentified ethic minorities, but excluding foreigners of Chinese nationality). The county-level administrative zoning map in 2010 was 
sourced from the Data Center for Resource and Environmental Science, Chinese Academy of Sciences (CAS). For the purpose of comparative analysis, the countylevel administrative divisions in 2010 (2353 units in total) are taken as the basic research units, the first five censuses are also unified into them. To ensure data comparability, the vector boundaries and demographic data of counties subject to change in administrative divisions are also integrated, referring to the Booklets of the People's Republic of China on Administrative Divisions from 1953 to 2010. Hong Kong, Macao and Taiwan, as well as Jinmen county are not considered in the study due to research needs and the lack of available data. Zhongsha Islands and Nansha Islands of the South China Sea are not covered as the census datasets include Xisha Islands only.

Using the spatial cutting technology from ArcGIS, this paper draws the Hu Line by connecting the geographic coordinate points of the two cities of Heihe and Tengchong and divides the Chinese territory into the southeast and northwest parts by extending the cutting line. With regard to spatial analysis of the demographic data, the population-density-based partitioning approach is used which divides the population according to the weighted area and is applied to counties and cities intersected by the $\mathrm{Hu}$ Line, while the demographic data are used directly for the others.

\section{Methods}

Population density and spatial autocorrelation models are introduced to examine the spatial distribution and correlation of minority populations in China, and a population gravity model and population concentration index are built to analyze the trends of changes in spatial distribution and spatial agglomeration characteristics of minority populations.

\section{Population concentration index}

This paper introduces the population concentration index to measure the tendency of minority population agglomeration or distribution at the level of districts and counties in the whole country. The formula is written as follows:

$$
C_{i}=\frac{1}{2} \sum_{j=1}^{n}\left|\frac{P_{i j}}{P_{i}}-\frac{S_{i j}}{S_{i}}\right|
$$

Where $P$ and $S$ stand for the country's total population and total land area respectively; $\underline{i}$ and $\underline{j}$ represent an ethnic group and a region respectively; $P_{i j}$ indicates the number of the $i$ population in region $j$ and $S_{i j}$, the area of the $i$ population in region $j$. A lower value closer to 0 means a decreased tendency toward population concentration in a certain region and more even distribution of populations. A greater value implies uneven distribution of populations (Gao 2003).

\section{Population distribution gravity center}

The population distribution gravity center refers to the equilibrium point in the geographical distribution of population within a particular region, reflecting the overall regional distribution situation. The formula is written as follows:

$$
\bar{x}=\frac{\sum_{1}^{n} p_{i} x_{i}}{\sum_{1}^{n} p_{i}} \bar{y}=\frac{\sum_{1}^{n} p_{i} y_{i}}{\sum_{1}^{n} p_{i}}
$$

Where $\bar{x}$ and $\bar{y}$ indicate the latitude and longitude coordinates of population gravity centers in a region, respectively; $p_{i}$ is the weight applied to the region $i$; $\bar{x}$ and $\bar{y}$ 
represent the center coordinates of the region $i$. With reference to the existing research findings (Gao 2003), the weighted size of a population is used for calculation, and $\bar{x}$ and $\bar{y}$ stands for the center coordinates of various county-level administrative areas.

\section{Overall spatial autocorrelation}

Overall spatial autocorrelation measures the degree of association between spatial features at the overall level and is usually expressed by Moran's I, written as follows:

$$
I=\frac{\sum_{i=1}^{n} \sum_{j=1}^{n} W_{i j}\left(X_{i}-\bar{X}\right)\left(X_{j}-\bar{X}\right)}{S^{2} \sum_{i=1}^{n} \sum_{j=1}^{n} W_{i j}}
$$

Where $n$ means the number of spatial units under study; $X_{i}$ and $X_{j}$ represent the attribute values of spatial unit $i$ and $j ; \bar{X}$ is the mean value of the attribute, and $S^{2}$ is the variance of value $\mathrm{X}$ and mean value $\bar{X}$; $W_{i j}$ stands for the spatial weight matrix.

\section{Local spatial autocorrelation}

The commonly used indicators of local spatial autocorrelation are G statistics and LISA. This paper uses $G_{i}^{*}$ to measure the local spatial autocorrelation, written as follows:

$$
G_{i}^{*}=\frac{\sum_{i=1}^{n} W_{i j} X_{j}-\bar{X} \sum_{j=1}^{n} W_{i j}}{\sqrt[s\left[\sum_{j=1}^{n} W_{i j}^{2}-\left(\sum_{j=1}^{n} W_{i j}\right)^{2}\right]]{n-1}}
$$

Where $W_{i j}$ stands for the spatial weight matrix; $X_{i}$ represents the attribute value of spatial unit $i$; $S$ is standard deviation and other variables are the same as in Formula (3). $G_{i}^{*}$ can detect local high-value and low-value clusters. A positive value of $G_{i}^{*}$ means highvalue spatial aggregation while a negative one of $G_{i}^{*}$ means low-value spatial aggregation.

\section{Results}

The spatial distribution pattern of minority populations in China Hu line-based distribution of Chinese minority populations

According to the sixth census, China's population reached 1.33972 billion in 2010, of which the minority population numbered 113.79 million, accounting for $8.49 \%$ of the total population of China. Compared with the 35.82 million found in the first census in 1953, the population of ethnic minorities has grown rapidly, with a rate much higher than the national average. From 1953 to 2010, the growth rate of the Han population was $124.91 \%$ and that of ethnic minorities as high as $222.17 \%$. There was also an upward trend in the proportion of the minority population as a whole, which increased from $6.06 \%$ in 1953 to $6.77 \%$ in 1982 , despite a slight decline in 1964 due to slower growth relative to the Han people, and it increased further, to $8.49 \%$, in 2010 (Table 1).

From a national perspective, the ethnic minorities were more likely to live in the east than in the west and, in 2010, were widely distributed with relative concentration. The minority population was mainly concentrated in the northeast, northwest, southwest and coastal areas. Using ArcGIS10.2, the Heihe-Tengchong line dividing the territory into the southeast and northwest parts is drawn for analysis of the minority population distribution, as shown in Table 2.

The southeast part of China is densely populated overall. Occupying only $43.36 \%$ of the territory, it accommodates $93.36 \%$ of the total population and $75.13 \%$ of the 
Table 1 Minority population in China from 1953 to 2010

\begin{tabular}{lllll}
\hline Year & $\begin{array}{l}\text { Total population } \\
(10,000)\end{array}$ & $\begin{array}{l}\text { Minority population } \\
(10,000)\end{array}$ & $\begin{array}{l}\text { Proportion of Minority } \\
\text { population }(\%)\end{array}$ & $\begin{array}{l}\text { Number of ethic } \\
\text { minority groups }\end{array}$ \\
\hline 1953 & 58,260 & 3532 & 6.06 & 41 \\
1964 & 69,458 & 3988 & 5.74 & 53 \\
1982 & 100,818 & 6723 & 6.67 & 55 \\
1990 & 113,368 & 9120 & 8.04 & 55 \\
2000 & 126,583 & 10,643 & 8.41 & 55 \\
2010 & 133,972 & 11,379 & 8.49 & 55 \\
\hline
\end{tabular}

minority population. In this region, the traditional territory for the Han people, the minority population makes up a small proportion, only $6.74 \%$, but the minority population density reaches 20.48 persons $/ \mathrm{km}^{2}$, about twice the national average and four times the northwest level (Table 2). The wide distribution of minority populations and concentration in certain areas give rise to several densely populated zones, including the Liaodong Peninsula, eastern Inner Mongolia, the northern part of the North China Plain, the southeastern coastal area, Yunnan-Guizhou Plateau, and the Hubei-Chongqing-Hunan intersection area.

In contrast, the sparsely populated northwest region, with $56.64 \%$ of the territory, contributes only $6.37 \%$ of the national population and $24.87 \%$ of the minority population. It is a traditional territory for the Uyghur, Tibetan, Hui and other ethnic minorities. The minority population accounts for $32.78 \%$ of the regional total. The regional population density is generally low due to relatively harsh natural environments and limited carrying capacity, coupled with large depopulated zones. People mainly live in environmentally superior areas such as valleys and oases, while the minority population mainly concentrates in the Hulunbeier Plateau, Ordos Plateau, Ningxia Plain, Huangshui Valley, western Sichuan Basin, southern Tibetan Valley, and the north and south edges of the Tianshan Mountains (Fig. 1).

As shown in Table 2, the Hu Line reveals a sudden change in the distribution of the national population and, to a certain extent, divides the ethnic minorities. $75.13 \%$ of the minority population lives in the southeast, slightly lower than its share in the total population. This demonstrates the uneven population distribution as implied by the $\mathrm{Hu}$ Line and the particularity of the minority population distribution.

\section{Overall spatial autocorrelation analysis of minority population distribution}

In order to examine the spatial heterogeneity and agglomeration of ethnic minorities in China, this paper analyzes the overall spatial autocorrelation of the minority population density in China. Using the Open-GeoDa software, the overall Moran's I value is

Table 2 Distribution of Chinese minority populations on both sides of the Hu Line in 2010

\begin{tabular}{lllllll}
\hline Region & $\begin{array}{l}\text { Proportion } \\
\text { of area (\%) }\end{array}$ & $\begin{array}{l}\text { Proportion of } \\
\text { the total } \\
\text { population (\%) }\end{array}$ & $\begin{array}{l}\text { Proportion of } \\
\text { minority } \\
\text { population (\%) }\end{array}$ & $\begin{array}{l}\text { Ratio of minority } \\
\text { population in } \\
\text { regional } \\
\text { population (\%) }\end{array}$ & $\begin{array}{l}\text { Regional population } \\
\text { density (person/km²) }\end{array}$ & $\begin{array}{l}\text { Minority population } \\
\text { density }\left(\text { person } / \mathrm{km}^{2}\right)\end{array}$ \\
\hline Southeast & 43.36 & 93.63 & 75.13 & 6.74 & 306.78 & 20.48 \\
Northwest & 56.64 & 6.37 & 24.87 & 32.78 & 15.76 & 5.19 \\
\hline
\end{tabular}




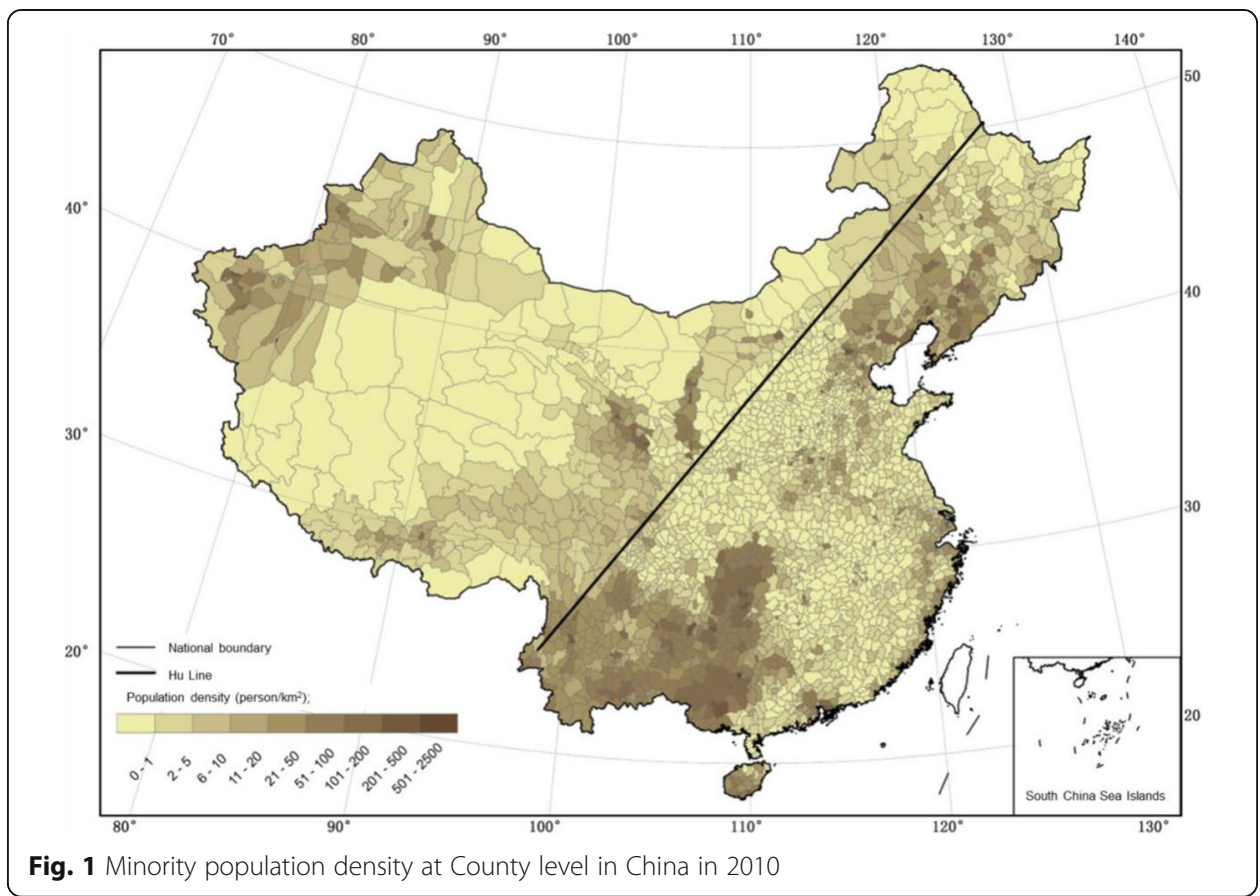

obtained for minority population density in the 2353 county-level administrative units covered by the six national censuses from 1953 to 2010 (Table 3).

The obtained Moran's I values are positive, indicating the positive spatial autocorrelation and significant spatial agglomeration. The Monte-Carlo simulation was used to test the significance of Moran's I value in Open-GeoDa and found the two-sided test value $\mathrm{Z}$ of standard normal distribution in the $99.9 \%$ confidence interval is about 3 . The values of minority population density in Table 3 are higher than the $Z$ value, which means that the Moran's I value is significant at the significance level of 0.001 and the statistical results are credible. The spatial association feature is that the low-density areas of ethnic minorities are adjacent and the areas with high density are adjacent, implying strong homogeneity of the spatial distribution of minority populations.

The overall Moran's I value exhibited a downward trend from 1953 to 2010, which indicated a decreased degree of agglomeration of minority populations in their traditional territories. This change may be attributed to migration stimulated by socio-economic development and household registration system reform. More specifically, the county-level spatial agglomeration of minority populations intensified during

Table 3 Estimation of Moran's I for Minority Population Density at County Level in China from 1953 to 2010

\begin{tabular}{lllll}
\hline Year & Moran's $I$ & $E(I)$ & $Z$-Value & $P$-value \\
\hline 1953 & 0.212985 & -0.0004 & 18.0059 & 0.001 \\
1964 & 0.35412 & -0.0005 & 27.6213 & 0.001 \\
1982 & 0.255158 & -0.0004 & 19.3622 & 0.001 \\
1990 & 0.226039 & -0.0004 & 18.765 & 0.001 \\
2000 & 0.250836 & -0.0003 & 19.5203 & 0.001 \\
2010 & 0.16264 & -0.0004 & 14.2779 & 0.001 \\
\hline
\end{tabular}


1953-1964, mirroring growing spatial dependency, but it tended to decrease during 1964-2010, despite a slight increase in 2010. In other words, there was large-scale spread following small-scale agglomeration. The minority population has maintained and continued the overall pattern of distribution amid changes from 1953 onwards.

\section{Local spatial autocorrelation analysis of minority population distribution}

The local spatial autocorrelation analysis compensates for the limitation of the Moran's I value not describing the pattern of spatial correlation of regional elements as a whole. This paper uses the Moran scatter plot to further examine the local spatial characteristics of the minority population density in China. The Moran scatter plot is divided into four quadrants: $\mathrm{HH}$ (high attribute values of a certain region and its surrounding regions), LH (low attribute value of a certain region and high attribute values of the surrounding regions), LL (low attribute values of a certain region and its surrounding regions), and HL (high attribute value of a certain region and low attribute values of the surrounding regions). Among them, quadrants $\mathrm{HH}$ and LL are spatially positively correlated, indicating strong homogeneity while quadrants LH and HL are negatively correlated, indicating strong heterogeneity.

Through statistical analyses on the Fig. 2, in 1953, there were $12.95 \%$ of the areas in quadrant $\mathrm{HH}$ for minority population density and $73.12 \%$ in quadrant LL, so

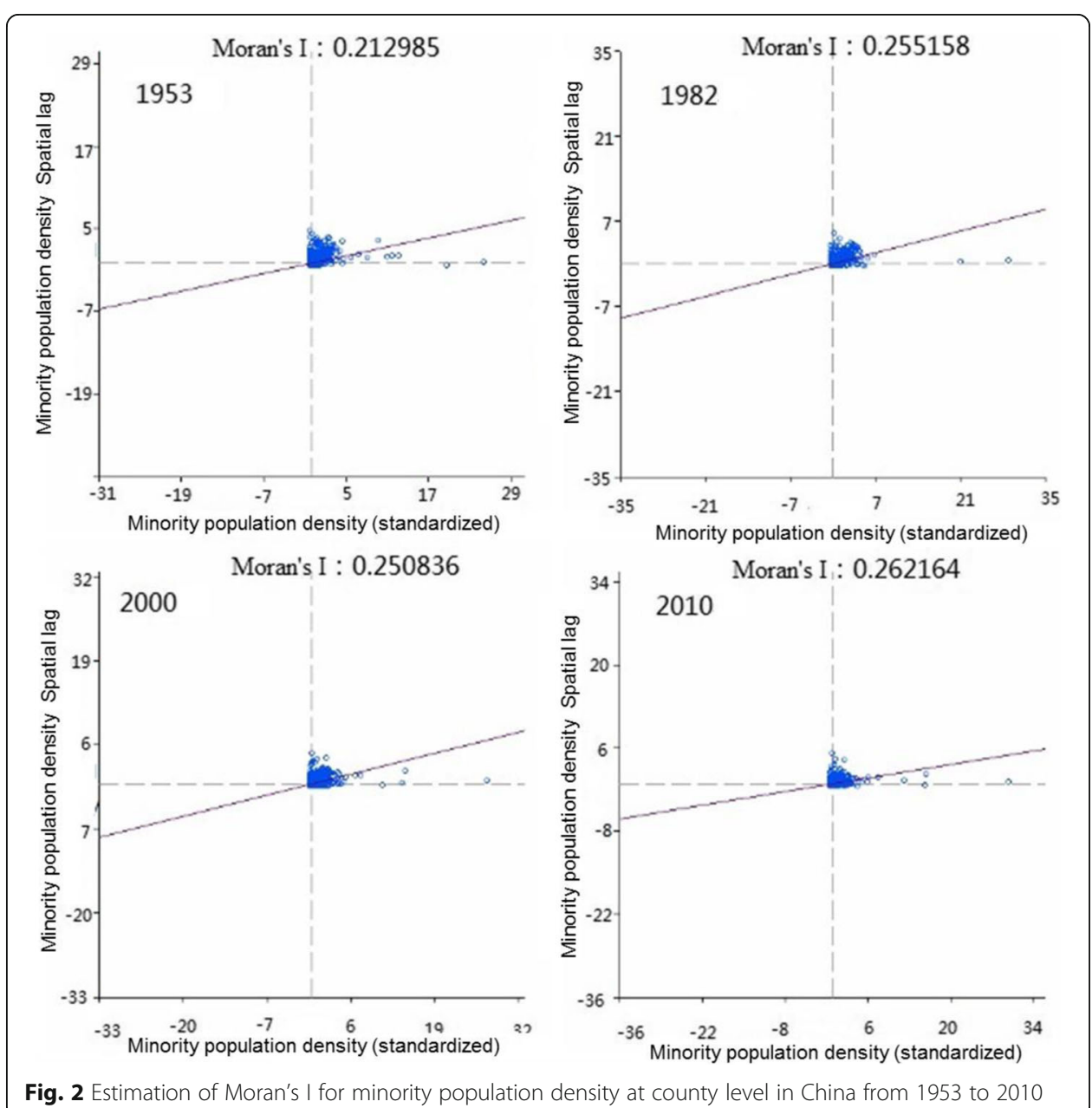

Fig. 2 Estimation of Moran's I for minority population density at county level in China from 1953 to 2010 
collectively $86.07 \%$ are positively correlated. In other words, the high-density areas were concentrated and the low-density areas were commonly adjacent. In 1990, the positive-correlated areas accounted for $86.96 \%$. The collective proportion did not change much, but the $\mathrm{HH}$ scattered points increased to $16.12 \%$ and the LL scattered points shrank to $70.84 \%$. The numbers of the spatially positively correlated areas decreased gradually. The proportion of spatially positively correlated areas fell to $84.93 \%, \mathrm{HH}$ and LL fell to 15.8 and $69.13 \%$ respectively in 2010 , mirroring a decreased concentration of ethnic minorities.

\section{Hot spot analysis of China's minority population}

$\mathrm{G}$ is an important index to distinguish high-value and low-value clusters. According to the local spatial autocorrelation formula, the hotspot analysis tool in ArcGIS10.2 is used to analyze the hotspots of the national minority population in space. There are some minor differences in the results of hotspot analysis when applying different spatial weight matrices in ArcGIS. The comparative analysis found that the first-order Rook spatial weight matrix can better identify the hotspots of minority population in China.

According to Formula (4), we get $\mathrm{Z}$ score from the $\mathrm{G}_{\mathrm{i}}^{\prime \prime}$ statistics at county level, and on this basis, a hot spot analysis chart for years 1953-2010 is drawn. Areas are divided according to the standard deviation of $Z$ value standard normal distribution at $1 \%$ significance level: significant hot spot with $Z$ value greater than 2, secondary hot spot with $Z$ value in the interval $[1,2]$, random distribution area with $Z$ value in the interval $[-1,-2]$, and significant cold spot with $Z$ value less than 2 .

The results show the 1953-2010 minority population hot spots in Liaodong Peninsula, Liaohe Plain, Ningxia Plain, Huangshui Valley, the south and north edges of the Tianshan Mountains, intersection of Hubei, Chongqing and Hunan, Yunnan-Guizhou Plateau and southern Hainan (Fig. 3). These hot spots roughly overlap with the traditional territories of ethnic minorities. The hot spot in Ningxia, which used to be a secondary hot spot in 1953, is closely related to the establishment of Ningxia Hui Autonomous Region in 1957, after which many Hui people from the countryside returned and lived in this favorable social and cultural environment. The formation of the Liaohe River hotspot can be attributed to the post-reform development of downstream Liaohe River Plain and large cities including Shenyang, which, with a large demand for labor, attracted a floating population of many ethnic minorities from the surrounding areas. With economic and social development, a number of minority population hotspots have risen, noticeably in some large cities. In 2000, Beijing evolved into a hot spot from a secondary hotspot in 1953 while Shanghai and Shenzhen became secondary hotspots. They stood out among hot spots in 2010 with the increasing concentration of ethnic minority floating populations. Apart from the above-mentioned hotspots, ethnic minorities are randomly distributed in most regions and form sporadic cold spots in East, South and Southwest China where the Han people traditionally live, as well as the northwest inland areas (mainly depopulated land). There are no significant cold spots, implying the wide distribution of minority population. It is predictable that 

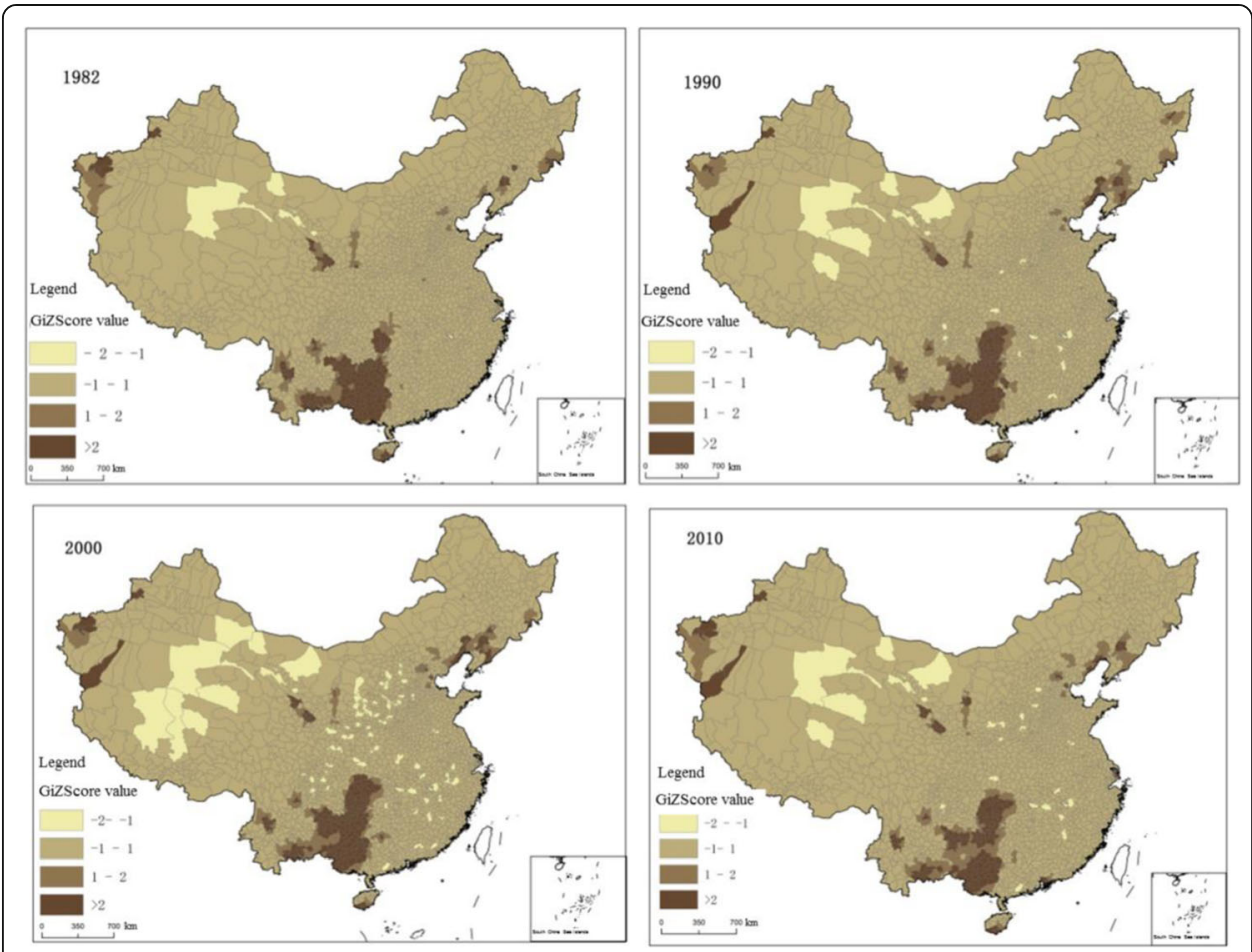

Fig. 3 The Hot Spot of Minority Population Density in China from 1953 to 2010

the cold spots will decrease owing to increasing mobility of ethnic minorities with further economic and social development.

\section{Spatial evolution of minority population}

\section{Population concentration index}

The concentration index of Han and minority populations can be calculated according to Formula (1) (Fig. 4). As shown in the Figure, the concentration index of the two groups exhibits a similar downward trend. The overall decline is probably because the demographic pattern has changed in a modest way with the migration of minority

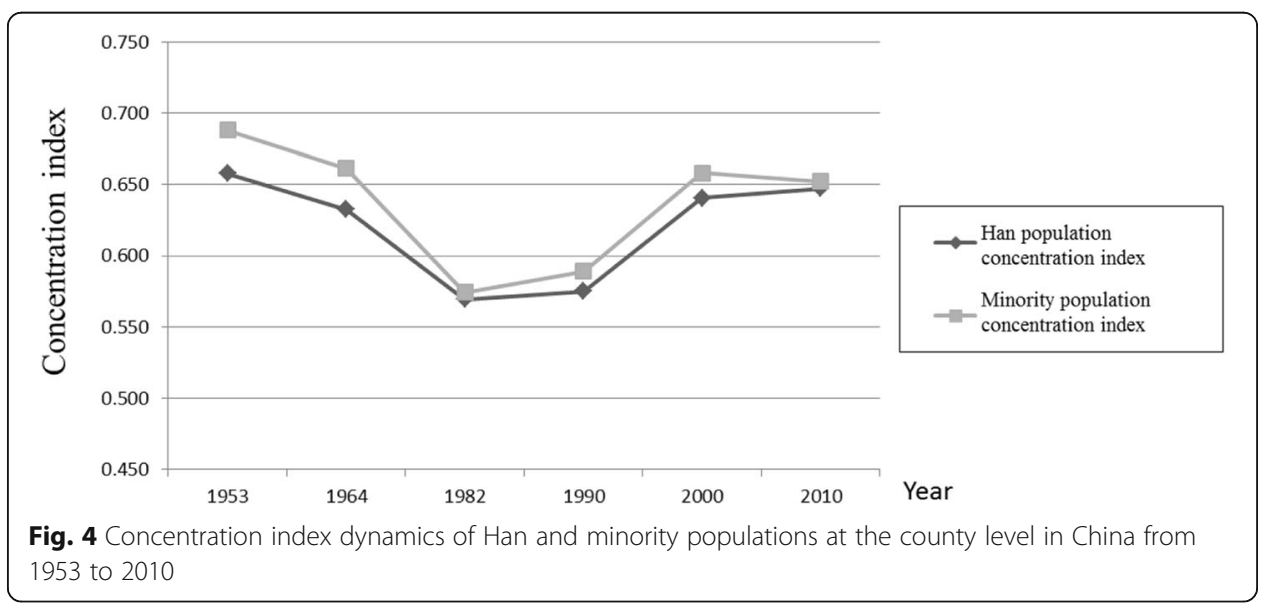


populations stimulated by social and economic development. The slight rise in 19822010 may be due to the concentration in some cities with rapid urban development after reform and opening. More specifically, during 1953-2010, the Han population concentration index fell from 0.658 to 0.647 amid fluctuations and this decline is marginal owing to the huge population base and wide distribution. It indicates the relatively balanced distribution of the Han population across the county and the ongoing move towards decentralization. In comparison, the minority population concentration index was larger and decreased more significantly amid fluctuations. It dropped from 0.688 to 0.652 during 1953-2010, representing a rate of 5.2\%, 3.6 percentage points higher than that of the Han population. Collectively speaking, the overall population distribution in China has not changed fundamentally and the pattern has remained stable, despite small differences in some areas.

\section{Minority population gravity center}

The spatial movement of the population center of gravity during 1953-2010 may reflect the dynamic evolutionary characteristics of the spatial distribution of minority populations. As shown in Fig. 5, (1) in 2010, the Han population center of gravity was located in Runan County, Zhumadian City, Henan Province and the minority population gravity center was in Cangxi County, Guangyuan City, Sichuan Province. Between the two, there is a linear distance of nearly $800 \mathrm{~km}$ and the latter is about one more degree of latitude south and eight more degrees of longitude west than the first. The location is in line with China's current pattern of population distribution. (2) The minority population center of gravity has actively changed, different from the relatively stable Han population center of gravity. The trajectory of movement can be divided into two phases. In the first phase (19531990), the minority population center of gravity shifted about $189 \mathrm{~km}$ northeast from $104^{\circ} 53^{\prime} 12.78^{\prime \prime} \mathrm{E}$ and $31^{\circ} 20^{\prime} 7.26^{\prime \prime} \mathrm{N}$ to $106^{\circ} 43^{\prime} 25.879^{\prime \prime} \mathrm{E}$ and $32^{\circ} 3^{\prime} 17.422^{\prime \prime} \mathrm{N}$. There are two reasons behind the change: (1) a large percentage of the minority

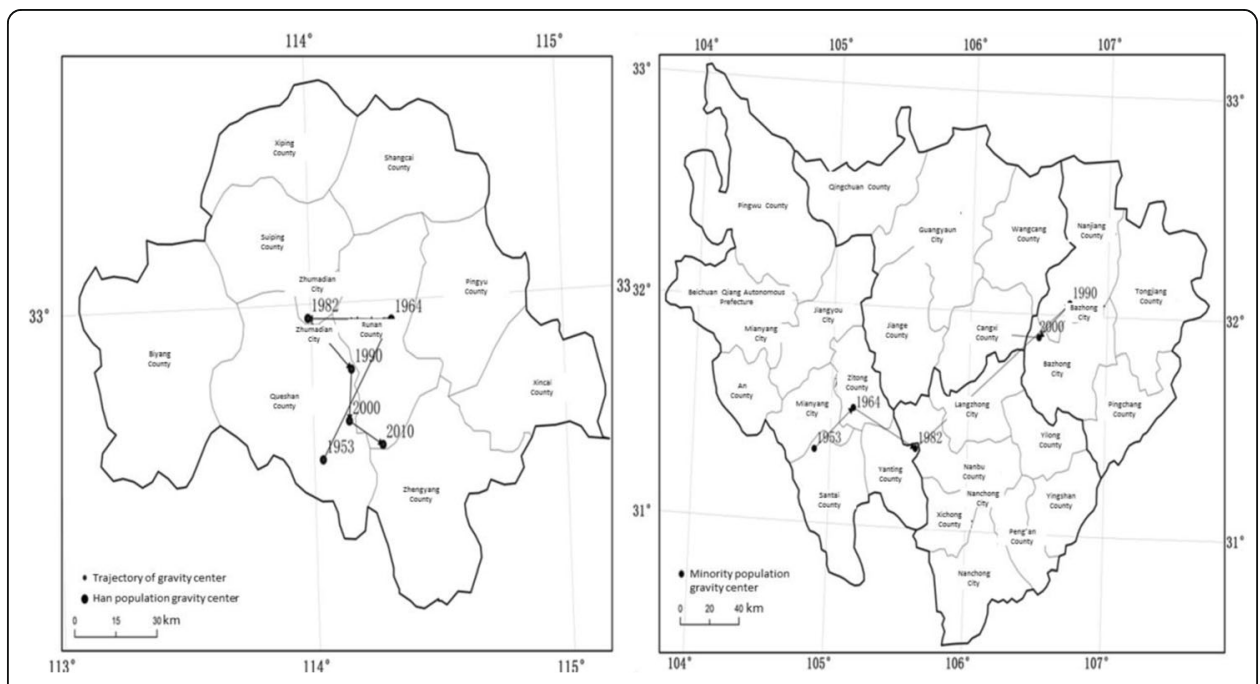

Fig. 5 Trajectory of change of population gravity center in China from 1953 to 2010 
population, mainly distributed east of the gravity center, were confirmed as the state carried out the restoration and alteration of ethnic composition under the influence of its ethnic group policy; (2) the household registration system reform, kicked off in the 1980s, lifted the shackles of population flow and put the eastern region on the right track of socio-economic development concurrent with the reform and opening up that thereby attracted the migration of ethnic minorities. In the second phase (1990-2010), the minority population center of gravity moved about $60 \mathrm{~km}$ southwest from $106^{\circ} 43^{\prime} 25.879^{\circ} \mathrm{E}$ and $32^{\circ} 3^{\prime} 17.422^{\prime \prime} \mathrm{N}$ to $106^{\circ} 6^{\prime}$ $23.678^{\prime \prime} \mathrm{E}$ and $31^{\circ} 54^{\prime} 20.212^{\prime \prime} \mathrm{N}$. The southwestward movement can mainly be attributed to more incremental movement of minority populations west of the center of gravity than those of the southeast area against the background of relaxed family planning policy, introduced in the 1980s in the ethnic minority areas.

\section{Proportion of minority populations on both sides of the $\mathrm{Hu}$ line}

The statistics show that during 1953-2010, the total population of mainland China swelled from 582.6 million to 1.33972 billion and the ratio of population in the southeast and northwest remained relatively stable. The changes in population on both sides of the $\mathrm{Hu}$ Line during this period are shown in Table 4. The proportion of the population living in the southeast continued to decrease slightly, down from $95.35 \%$ in 1953 to $93.63 \%$ in 2010, while the proportion in the northwest continued to increase slightly, up from $4.65 \%$ in 1953 to $6.37 \%$ in 2010 .

At the same time, the ratio of minority populations on the sides of the $\mathrm{Hu}$ Line stayed at 75:25. In 1953, the minority population accounted for $73.5 \%$ in the southeast and $26.5 \%$ in the northwest, and in 2010, the numbers became 75.13 and $24.87 \%$. In these decades, the proportion of minority populations collectively increased by only 1.63 percentage points, 1.72 percentage points lower than that of the total population. The six census datasets also show, the southeast and northwest ratio of minority populations remained at 75:25. In comparison, the southeast has always maintained a significant population size relative to the northwest. In addition, the southeast and northwest ratio of minority population density stayed around 5. Thus, to some extent, the $\mathrm{Hu}$ Line mirrors a sudden change of the minority population in China.

Table 4 Distribution of Chinese minority population on both sides of the Hu Line from 1953 to 2010

\begin{tabular}{|c|c|c|c|c|c|c|}
\hline & \multicolumn{2}{|c|}{$\begin{array}{l}\text { Proportion of regional } \\
\text { population }\end{array}$} & \multicolumn{2}{|c|}{$\begin{array}{l}\text { Proportion of minority } \\
\text { population }\end{array}$} & \multicolumn{2}{|c|}{$\begin{array}{l}\text { Ratio of minority population } \\
\text { in the regional population }\end{array}$} \\
\hline & Southeast & Northwest & Southeast & Northwest & Southeast & Northwest \\
\hline 1953 & 95.35 & 4.65 & 73.5 & 26.5 & 4.97 & 36.74 \\
\hline 1964 & 94.92 & 5.08 & 73.57 & 26.43 & 4.41 & 29.61 \\
\hline 1982 & 94.21 & 5.79 & 74.99 & 25.01 & 5.14 & 25.02 \\
\hline 1990 & 94.06 & 5.94 & 77.31 & 22.69 & 6.64 & 30.87 \\
\hline 2000 & 93.83 & 6.17 & 77 & 23 & 6.95 & 31.55 \\
\hline 2010 & 93.63 & 6.37 & 75.13 & 24.87 & 6.74 & 32.78 \\
\hline
\end{tabular}




\section{Major minority population groups on both sides of the Hu line}

According to statistics, in 2010, the population of the Uyghur, Mongolian, Tibetan, Zhuang and Hui ethnic groups totaled 49.85 million, accounting for $44.52 \%$ of the total minority population. The population changes of the five ethnic groups on both sides of the Hu Line are shown in Table 5. Due to the geographical position of traditional territories, up to $99 \%$ of the Uyghur population and $96 \%$ of the Tibetan population are distributed in the northwest while the Mongolian and Zhuang populations are mainly distributed in the southeast of the Hu Line, representing 71 and $99 \%$ respectively. As to the Hui population, the distribution is more balanced on the sides of the $\mathrm{Hu}$ Line.

In terms of population changes, during 1953-2010, the proportion of major minority population groups continued to increase moderately in the southeast and fall slightly in the northwest. Different from the overall trend of minority population, the major minority population groups, except the Hui ethic group, maintained a modest growth in their traditional territories. There was a light increase in the proportions of Uyghur and Tibetan populations in the northwest and the Mongolian and Zhuang population in the southeast. The proportion of the Hui population changed significantly on both sides due to strong mobility. It climbed from 48.44 to $57.02 \%$ in the southeast during 1953-2010, making a total increase of 8.58 percentage points. It is evident that the imbalance and ultra-stability of minority population distribution are also profoundly manifested in the major ethnic minorities.

The distribution of minority populations in China tends to be stable. However, with the social and economic development and the progress of urbanization, the flow and migration of ethnic minorities has become more and more active, presenting a noticeable trend of eastward spread. For example, more than $99 \%$ of the Uyghur population live in the traditional area of Xinjiang. In 1953, the Uyghur people were found in only 5.7\% of the districts and counties of the country, including Taoyuan County, Hunan Province, but they tended to spread eastward slightly in 1984 and to the countryside in 2000. The statistics show that in 2010, more than 70\% of the districts and counties had Uyghur populations.

\section{Discussion}

According to qualitative and quantitative analysis, the important factors that affect the changes of Chinese minority populations on both sides of the $\mathrm{Hu}$ Line are identified to include the natural environment, social and historical conditions, ethnic and population policy and regional economic disparities. Due to data availability and quality, the data after the year 2000 is used for quantitative analysis.

Table 5 Distribution of major minority population groups on both sides of the Hu Line from 1953 to 2010

\begin{tabular}{|c|c|c|c|c|c|c|}
\hline & \multicolumn{2}{|l|}{1953} & \multicolumn{2}{|l|}{1990} & \multicolumn{2}{|l|}{2010} \\
\hline & Southeast & Northwest & Southeast & Northwest & Southeast & Northwest \\
\hline Total minority population & 73.5 & 26.5 & 77.31 & 22.69 & 75.13 & 24.87 \\
\hline Uyghur & 0.64 & 99.36 & 0.2 & 99.8 & 0.06 & 99.94 \\
\hline Mongolian & 71.46 & 28.54 & 72.23 & 27.77 & 73.35 & 26.65 \\
\hline Tibetan & 3.2 & 96.8 & 2.12 & 97.88 & 1.05 & 98.95 \\
\hline Zhuang & 99.93 & 0.07 & 99.94 & 0.06 & 100 & 0 \\
\hline Hui & 48.44 & 51.56 & 52.47 & 47.53 & 57.02 & 42.98 \\
\hline
\end{tabular}


The natural environment is the primary factor affecting population distribution. In the long history of mankind, people tend to choose water-rich areas with a warm and humid climate. Most of the southeast is warm and humid while the northwest is largely cold and dry. Given China's stable natural environment over the years, minority populations on both sides of the Hu Line show reliable characteristics of large numbers. The research on the relationship between population distribution and geographical factors has produced a lot of outcomes (Hu 1935; Zhang and Zeng 2005; Lv 2010), though these will not be detailed here.

Historical conditions established the basic pattern of national population distribution. The geographical pattern of distribution of various ethnic groups in China has gradually taken shape in the historical process of several thousand years and includes the traditional areas supporting a concentration of ethnic groups. This well-founded basic pattern is that the Han population is mainly distributed in the central plains and the eastern region and other ethnic populations are in the western inland areas.

Population policy is an important part of the change in the population of ethnic groups in the southeast and the northwest of China. The family planning policy, implemented as a basic national policy since the 1980s, has exerted a profound impact on the birth rate and natural population growth rate. As the policy is more relaxed in the ethnic minority areas, the northwest with a higher proportion of minority population has a considerable advantage in the regional natural growth rate. According to the dataset of the $6^{\text {th }}$ census in 2010, the average natural growth rate of the population in Xinjiang, Tibet, Ningxia, Gansu and Qinghai in the northwest registered 7.86\%, 1.63 times of the national average of $4.81 \%$ during the same period. The growth rate was $4.66 \%$ in the southeast, lower than the national average. Owing to a high natural growth rate, the northwest witnessed a slight increase in both the proportion of regional population in the countryside and the proportion of minority population in the region.

The level of economic development directly influences the mechanical growth of the minority population on both sides. With advanced economic development, the southeast exhibits significantly higher migration intensity than the northwest. The statistics show that in 2010, 90\% of China's population inflow and outflow occurred in the southeast, while the ethnic minorities constituted only $2.62 \%$ of the national floating population. In other words, the vast majority of China's population flows were digested internally in the southeast. In 2010, there was a weak positive correlation between per capita GDP and minority population growth in the southeast, as shown in Fig. 6a. The

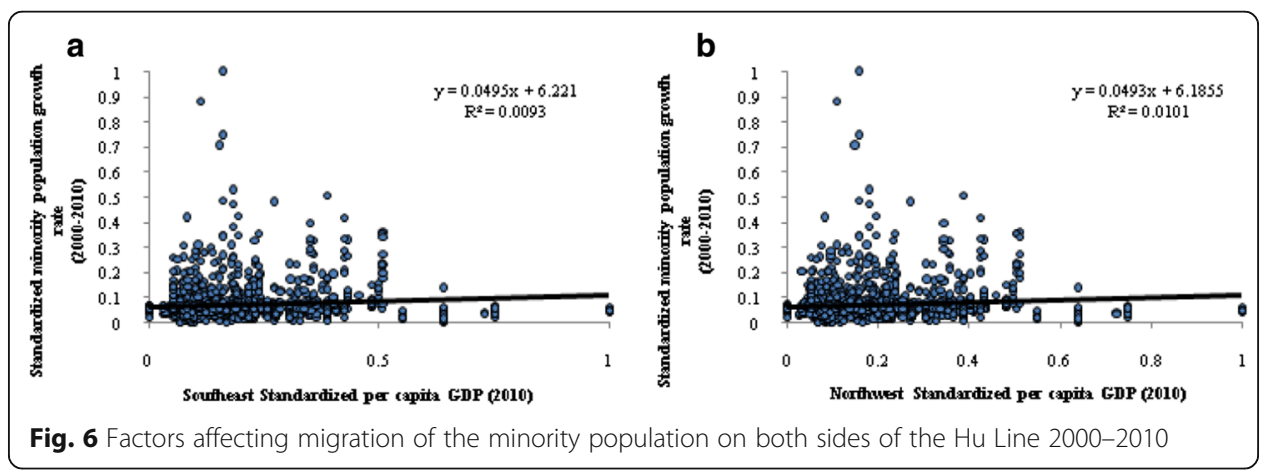


coefficient of determination $R^{2}$ reads only 0.0093 , presenting a low degree of explanation. In the northwest, however, the relationship is not very significant and the coefficient of determination $\mathrm{R}^{2}$ reads only 0.0101 with a low degree of explanation, as shown in Fig. 6b. Although the current regional economic disparities have little influence on the increment of minority population, the impact on its proportion on both sides of the $\mathrm{Hu}$ Line will gradually appear with increased migration to the southeast coastal areas.

Ethnic policy is another significant factor. China carried out the restoration and alteration of ethnic composition during the 1960s-1980s. According to relevant statistics, more than 12 million people have reclaimed or changed their ethnic identities since 1982. With the implementation of this policy, the population of ethnic minorities grew rapidly. In the last 1964-1982 years, the population of Tujia people in Hubei and Chongqing increased by 4.14 times. Hubei's proportion of the national minority population increased from 0.46 to $2.68 \%$ and Hunan's, from 2.68 to $3.31 \%$. Under the impact of the policy, the central region increased its proportion of minority population and the proportion of minority population in southeastern China increased by one percentage point.

\section{Conclusions}

Based on GIS spatial analysis, this paper has built a county-based spatial database covering six national censuses conducted during 1953-2010 and analyzed minority population distribution and its changes on the whole and on both sides of the $\mathrm{Hu}$ Line, considering spatial characteristics and evolution. It came to the following conclusions:

(1)The spatial pattern of China's minority population has been formed through a historical process and relates very closely with the current status of socio-economic development. As a result, the basic differences between ethnic groups will still exist in the foreseeable future. With progress in the economy, society and urbanization, the ethnic minority areas will be greatly developed. The redistribution of minority population will change with increasing population movements. However, the overall distribution pattern of minority populations and the relative backward situation of ethnic areas will be maintained for a long time.

(2)China's minority population is unevenly distributed with significant spatial clusters. There are a number of hot spots in the traditional areas of distribution and some emerging hot spots in the eastern large cities. Hot spots in the northeast, northwest, southwest, and southeast coastal areas, as well as some cities verify the imbalance of minority population distribution and indicate the particularity of high concentration in the traditional areas. Economic and social factors have a significant impact on the formation of new hot spots.

(3) The pattern of Chinese minority population distribution is extraordinarily stable. In 1953 , the proportion of minority population accounted for $73.5 \%$ in the southeast and $26.5 \%$ in the northwest, and the numbers changed to 75.13 and $24.87 \%$ in 2010 . In these years, the proportion of minority population collectively increased by only 1.63 percentage points. The southeast and northwest ratio of minority populations mainly remained at 75:25. In addition, the southeast and northwest ratio of minority 
population density stabilized around 5. To some extent, the Hu Line represents a line of sudden change in the Chinese minority population.

(4)Chinese minority populations are widely distributed with an evident tendency of spread to the eastern region and even the whole country. The concentration of minority populations in certain areas is also noticeable, presenting a higher concentration index than the Han population. Compared with the first census, there is a great improvement in the closed state owning to strengthened mobility, especially in the last 30 years.

(5)Mixed habitation will become more common as exchanges intensify among different ethnic groups. With the migration of minority populations to the eastern region and throughout the countryside, the close ties, frequent exchanges, and population flows in an increasing scale will deepen mutual understanding and enhance national integration and unity, contributing to national common prosperity.

In the current context of new economic normality, the development of ethnic minority areas is inseparable from rational population distribution. The scientific distribution of minority populations requires efforts in two aspects: a) to develop the economy according to local circumstances and speed up new urbanization of ethnic minority areas; and b) seizing the opportunity brought by the "One Belt and One Road" initiative, to guide the ethnic minority areas to rationalize population distribution and industrial layout, promote economic restructuring and upgrading, and foster new economic growth points, to narrow regional economic differences towards common development and prosperity of all ethnic groups.

\footnotetext{
Acknowledgements

We are grateful to the National Natural Science Foundation of China and the Ministry of Education Humanities and Social Science Fund for their support.

Funding

This paper is a stage result of the "Study on Increase of Urbanization Rate of Household Population" (PN: 15ZDC035), a major project of National Social Science Foundation, "Study on the Citizenization of New Generation Migrant Workers" (PN: 14AZD027), a key project of National Social Science Foundation, and "Study on the Objectives and Paths of Social Integration to Improve the Quality of Urbanization" (PN: 11JJDZH001), a major project of the Research Base for Humanities and Social Sciences under the Ministry of Education.
}

Authors' contributions

$\mathrm{XG}$ is responsible for the overall design of the article and revised the article; XW is responsible for the data collection and analysis part; BZ is responsible for the literature review and conclusion. All authors read and approved the final manuscript.

Competing interests

We declare that we have no competing interests.

\section{Author details}

${ }^{1}$ School of Public Administration, The Center for Modern Chinese City Studies, East China Normal University, No. 3663, Zhongshan North Road, Putuo District, Shanghai, China. ${ }^{2}$ School of Public Administration, School of Social Development East China Normal University, No. 500, Dongchuan Road, Minhang District, Shanghai, China. ${ }^{3}$ Shanghai Business School, No. 2271 Zhongshan West Road, Xuhui District, Shanghai, China.

Received: 4 August 2017 Accepted: 8 September 2017

Published online: 18 December 2017

References

Ding, Jinhong, and Shujin He. 2015. Population geography and the future of urbanization in China: Symposium for commemorating the 80th anniversary of the discovery of Hu Huanyong line in Shanghai. Acta Geographica Sinica 12: 1856.

Dong, Chun, Jiping Liu, Rong Zhao, and Guixin Wang. 2002. An discussion on correlation of geographical parameter with spatial population distribution. Pemote Sensing Information 4: 30-35.

Feng, Zhiming, Yan Tang, Yanzhao Yang, and Dan Zhang. 2007. The relief degree of land surface in China and its correlation with population distribution. Acta Geographica Sinica 10: 1073-1082.

Gao, Xiangdong. 2003. Population change and urbanization in metropolis. Shanghai: Fudan University. 
Gao, Xiangdong, and Beiqian Zhu. 2014. The research of city's minority floating population practitioners of Muslim ramen museum: Taking shanghai as an example. Journal of South-Central University for Nationalities (Humanities and Social Sciences) 1: 26-32.

Ge, Meiling, and Zhiming Feng. 2002. Study on the distribution pattern of China's population in 2000 based on GIS: In contrast to the study of Hu Huanyong in 1935. Population Research 4: 51-57.

Guo, Wei. 2014. The population trend of the ethnic groups in contemporary China:2000 2010. Population Journal 6: 13-21.

Hu, Huanyong. 1990. The distribution, regionalization and prospect of China's population. Acta Geographica Sinica 2: 139-145.

$\mathrm{Hu}$, Huanyong. 1935. Distribution of the population in China: With statistical tables and density maps. Acta Geographica Sinica 2: 33-72.

Jiao, Kaishan. 2014. A spatial statistical analysis of the distribution and change of the population of China's ethnic minorities. Journal Of Southwest University for Nationalities (Humanities and Social Sciences) 10: 26-32.

Jin, Feng. 2005. The status, characteristics and problems of minority population in Liaoning Province. Manchu Minority Research 2: 11-23.

Li, Hongjie. 1995. Several quantitative analysis of migration of minority population. Manchu Minority Research 3: 53-59.

Li, Yuting, Sibao Ding, and Rongcheng Wang. 2009. Geographical cost and the population distribution pattern. China Population Pesources and Envieonment 5: 82-87.

Liu, Congfen, Weizhou Zhong, Ruiqing Liu, and Ruirong Zhang. 2010. A spatial statistical analysis on distribution of minority of Yunnan Province. Statistics and Information Forum 11: 97-93.

Liu, Jiyuan, Tianxiang Yue, Yingan Wang, Dongsheng Qiu, Mingliang Liu, Xiangzheng Deng, Xiaohuan Yang, and Yujie Huang. 2003. Digital simulation of population density in China. Acta Geographica Sinica 1: 17-24.

Liu, Ruiwen, Zhiming Feng, Yanzhao Yang, and Zhen You. 2010. Research on the spatial pattern of population agglomeration and dispersion in China. Progress in Geography 10: 1171-1177.

Liu, Taihong. 2001. The influence of population migration on population distribution and on forming Aihui-Tengchongline. Market and Demographic Analysis 4: 30-35.

Lo, C.P. 2001. Modeling the population of China using DMSP operational linescan system nighttime data. Photogrammetric Engineering and Remote Sensing 67: 1037-1048.

Lu, Shouting. 2009. Analysis of population migration and mobility of minority nationalities in the process of urbanization in the northeast of China. Manchu Minority Research 1: 1-7.

Luo, Weixiang. 2008. Population distribution and its changes of the ethnic minorities. South China Population 1: 42-50.

Lv, Chen .2010. Mechanism research on the process of population spatial collection and distribution. Beijing: University of Chinese Academy of Sciences Press.

Ma, Rong. 2000. The distribution of minority groups in Kashi, Xinjiang. Northwestern Journal of Ethnology 2: 101-111.

Ma, Zongbao, and Yinghua Jin. 1997. Changing spatial pattern of Hui and Han nationalities and its impact on their social interchange. The Hui Studies 2: 19-30.

Shan, Feifei .2006. The pattern of living and the relationship between ethnic groups in Yining. Lanzhou: Lanzhou University Press.

Tian, Yongzhong, Shupeng Chen, Tianxiang Yue, Lifen Zhu, Yingan Wang, Zemeng Fan, and Shengnan Ma. 2004. Simulation of China population density based on Landuse. Acta Geographica Sinica 2: 283-292.

Wang, Jing'ai. 1998. The population distribution and the choice of sustainable development model in China. Journal of Beijing Normal University (Social Sciences) 2: 72-80.

Wang, Zheng. The two keys to break the "Hu Huanyong line", WenHui Po ( page 2), 2014.

Wang, Guixin. 1997a. Population distribution and regional economic development in China: A new approach of population distribution economics. Shanghai: East China Normal University.

Wang, Junmin. 1997b. Migration and spatial pattern of ethnic population in Hohhot. N. W. Minorities Research 2: 7-27.

Yuan, Huarong. 1993. Study on the rationality of Chinese population distribution. Geographical Research 1: 64-69.

Zhang, Shanyu, and Mingxing Zeng. 2005. The distributional change and the migration situation of the ethnic population: An analysis of the data from China's fifth census of 2000. Ethno-National Studies 1: 17-25.

Zhang, Yongyue, Yanjiao Song and Zhang Chuanyong. 2015. The New Urbanization and the Possibility of Breaking through the "HU Line". Journal Of East China Normal University (Humanities and Social Sciences) 2: 101-112.

Zhao, Shu. 1993. Analysis of status of minority population in Beijing. Journal of Central University for Nationalities 4: 18-27.

Zheng, Changde. 2013. Growth and distribution of China minority population since 2000. Northwest Population 2: 1-5.

Zhuo, L., T. Ichinose, J. Zheng, J. Chen, P.J. Shi, and X. Li. 2009. Modelling the population density of China at the pixel level based on DMSP/OLS non-radiance-calibrated night-time light images. International Journal of Remote Sensing 30: 1003-1018.

Zhuo, Li, Jin Chen, Peijun Shi, Zhihui Gu, Yida Fa, and Ichinose Toshiaki. 2005. Modeling population density of China in 1998 based on DMSP/OLS nighttime light image. Acta Geographica Sinica 2: 266-275.

\section{Submit your manuscript to a SpringerOpen ${ }^{\circ}$ journal and benefit from:}

- Convenient online submission

- Rigorous peer review

- Open access: articles freely available online

- High visibility within the field

- Retaining the copyright to your article

Submit your next manuscript at $\gg$ springeropen.com 